\title{
Intestinal transit in anxiety and depression
}

\author{
D A Gorard, J E Gomborone, G W Libby, M J G Farthing
}

\begin{abstract}
Background-Patients with anxiety and depression often have bowel symptoms. Until now, studies investigating a link between altered bowel habit and psychological illness have focused on patients with disturbed defecation presenting to gastroenterologists.
\end{abstract}

Aims-To determine whether patients with anxiety and depression have objective evidence of abnormal intestinal transit irrespective of any bowel symptoms.

Methods-21 psychiatric outpatients fulfilling research criteria for generalised anxiety disorder and/or major depression, and 21 healthy volunteers were studied. Orocaecal transit time (OCTT) was measured by lactulose hydrogen breath test. Whole gut transit time (WGTT) was measured by abdominal radiography after ingestion of radio-opaque markers.

Results-Median (range) WGTT was shorter in patients with anxiety (14 (6-29) hours) than in patients with depression (49 (35-71) hours) ( $p<0.001)$, and controls (42 $(10-68)$ hours) $(p<0.001)$. In patients with anxiety, orocaecal transit time was shorter (60 (10-70) minutes) than in patients with depression (110 (60-180) minutes) $(p<0.01)$, and shorter than in controls (75 (50-140)) minutes $(p<0 \cdot 05)$. The prolongation of transit times in depression compared with controls was not significant. However, WGTT correlated with both the Beck Depression Inventory score $(r=0.59, p<0.01)$ and the depression score of the Hospital Anxiety and Depression scale $(r=0.66, p<0.001)$. Conclusions-These objective measurements of intestinal transit in affective disorders are consistent with clinical impressions that anxiety is associated with increased bowel frequency, and depressed patients tend to be constipated; mood has an effect on intestinal motor function. (Gut 1996; 39: 551-555)

Keywords: intestinal transit, anxiety, depression, orocaecal, constipation.

Digestive Diseases Research Centre, St Bartholomew's and the Royal London School of Medicine and Dentistry, London D A Gorard

JE Gomborone

JE Gombor Libby

M J G Farthing

Correspondence to: Dr D A Gorard, Wycombe General Hospital, High Wycombe, Bucks HP11 2TT

Accepted for publication 28 May 1996
An association between disturbed bowel habit and psychological distress is suggested by the high prevalence of psychiatric disturbance in patients with irritable bowel syndrome attending hospitals. ${ }^{1-3}$ Similarly, patients with severe constipation have increased psychiatric morbidity ${ }^{4-7}$ particularly depression. ${ }^{8}$ By contrast with such studies in patients with bowel symptoms presenting to gastroenterology clinics, there has been little objective work looking at the converse - namely, altered bowel function in psychiatric patients. Patients with anxiety and depression often have disturbed defecation among their somatic symptoms and constipation is common in depression, ${ }^{9}$ but objective studies of intestinal transit in patients with psychiatric illness are lacking. The aim of this study was to see whether patients with anxiety or depression, or both, had evidence of abnormal intestinal transit irrespective of any bowel symptoms.

\section{Methods}

\section{PATIENTS}

Consecutive outpatients attending a general psychiatry clinic who fulfilled DSM-III-R criteria $^{10}$ for major depression and/or generalised anxiety disorder were invited to participate in the study. Only patients who were taking no medication were studied, as many drugs, and particularly psychotropic drugs ${ }^{11}$ alter bowel motor function. Bowel symptoms were not necessary for entry into the study. Except for the purposes of this study, these patients were not seeing gastroenterologists. Patients who were suicidal, psychotic, or who needed admission to hospital or immediate drug treatment were excluded.

\section{CONTROL SUBJECTS}

Healthy volunteers were studied as a control group. These controls were members of staff or medical students, were not taking any medication, and had no history of gastrointestinal or psychiatric disturbance. The control group was age and sex matched with the patients because colonic transit time is greater in females than in males. ${ }^{11} 12$

All patients and healthy controls underwent: (a) psychological assessment, (b) measurement of whole gut transit time (WGTT), and (c) measurement of orocaecal transit time (OCTT). All subjects gave written consent and the study was approved by the research ethics committee of the City and Hackney Health District.

PSYCHOLOGICAL ASSESSMENT

Each subject was assessed by a psychologist (JEG) who performed a structured clinical interview ${ }^{13}$ looking for criteria fulfilling DSMIII-R diagnoses of major depression and generalised anxiety. ${ }^{10}$ Subjects then also completed validated self report questionnaires, the Beck Depression Inventory (BDI) ${ }^{14}$ and the Hospital Anxiety and Depression scale $(\mathrm{HAD})^{15}$ providing details of their mood. The HAD can be divided into a subscale for anxiety (HAD-A) and a subscale for depression (HAD-D). 
TABLE I Psychiatric questionnaire scores in patients with DSM-III-R criteria for major depression or generalised anxiety disorder and in control subjects

\begin{tabular}{lllll}
\hline & Patients $(n=21)$ & Controls $(n=21)$ \\
\cline { 2 - 4 } & Anxiety $(n=8)$ & Depression $(n=9)$ & Anxiety and depression $(n=4)$ & \\
\hline BDI & $11 \cdot 5(7-19)$ & $25(10-41)$ & $19 \cdot 5(18-22)$ & $1(0-7)$ \\
HAD-A & $15(11-17)$ & $12(7-18)$ & $15(11-16)$ & $4(1-5)$ \\
HAD-D & $5 \cdot 5(2-10)$ & $11(9-18)$ & $13(10-15)$ & $1(0-4)$ \\
\hline
\end{tabular}

Values are median (range). BDI=Beck Depression Inventory; HAD-A=Hospital Anxiety and Depression score: anxiety subscale; HAD-D=Hospital Anxiety and Depression score: depression subscale. time elapsed between lactulose ingestion and a sustained ( $>10 \mathrm{ppm}$ above baseline) rise in breath hydrogen.

BOWEL SYMPTOMS

Subjects completed an abridged version of a validated bowel symptom questionnaire. ${ }^{16} 17$ This asked them to describe their weekly frequency of defecation as $\leq 1,2,3-4,5-8$, $9-12,13-16,17-21,22-26$, or $>26$, and enquired about the presence of abdominal pain and Manning criteria ${ }^{18}$ for diagnosing irritable bowel syndrome.

The WGTT was measured by a radio-opaque marker technique using a single abdominal radiograph. Subjects swallowed 20 radioopaque polyvinyl chloride markers on three consecutive mornings at 0900 hours. On the fourth morning, a plain abdominal radiograph was taken at 0900 hours. The WGTT was calculated by multiplying the total number of markers seen by 1.2 as previously described. ${ }^{12}$ Segmental colonic transit times were calculated from the numbers of markers seen within the left colon, right colon, and rectosigmoid regions.

OROCAECAL TRANSIT TIME

After an overnight fast and $20 \mathrm{ml}$ mouth rinse with $0.2 \% \mathrm{w} / \mathrm{v}$ chlorhexidine gluconate, subjects ingested $20 \mathrm{ml}(13.4 \mathrm{~g})$ lactulose. End expiratory breath samples were collected before and at 10 minute intervals after lactulose ingestion. Hydrogen concentration in each breath sample was determined using an electrochemical detector (GMI Medical Ltd, Renfrew, UK). The OCTT was defined as the

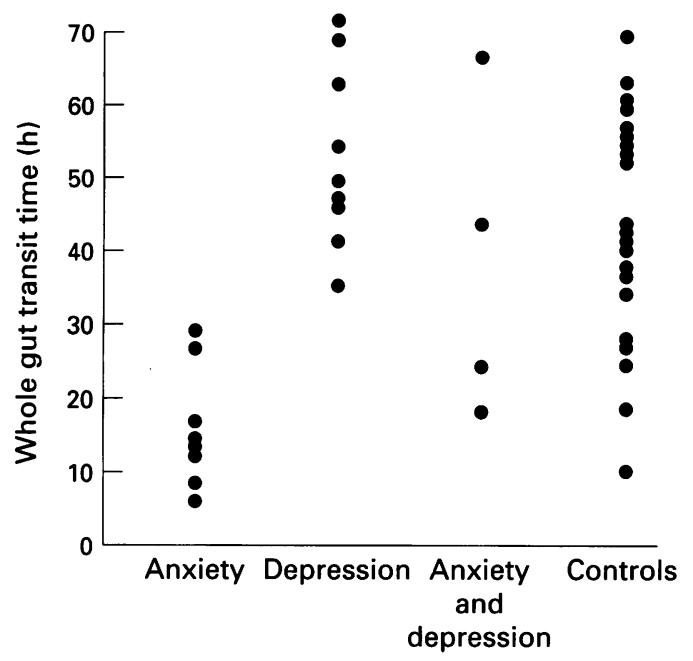

Figure 1: Whole gut transit times in patients with $D S M-I I I-R$ criteria of generalised anxiety disorder, or major depression, or both, and in controls.

TABLE II Segmental colonic transit times in controls and in patients with generalised anxiety or major depression

\begin{tabular}{lllll}
\hline & $\begin{array}{l}\text { Right colon } \\
\text { transit time }\end{array}(h)$ & $\begin{array}{l}\text { Left colon } \\
\text { transit time }(h)\end{array}$ & $\begin{array}{l}\text { Rectosigmoid } \\
\text { transit time }(h)\end{array}$ & $\begin{array}{l}\text { Wholegut (total colon) } \\
\text { transit time }(h)\end{array}$ \\
\hline Controls $(\mathrm{n}=21)$ & $11(2-27)$ & $14(0-37)$ & $15(4-32)$ & $42(10-68)$ \\
Anxiety $(\mathrm{n}=8)$ & $4(0-13)$ & $2(0-11)$ & $4(0-10)$ & $14(6-29)$ \\
Depression $(\mathrm{n}=9)$ & $16(1-29)$ & $14(0-39)$ & $11(2-29)$ & $49(35-71)$ \\
\hline
\end{tabular}

Values are median (range).

\section{Results}

Twenty one patients (five men, median age 27, range $17-45$ years) with DSM-III-R criteria for major depression, or generalised anxiety disorder, or both were recruited. Eight had anxiety, nine had depression, and four had research criteria of both generalised anxiety and depression. Twenty one healthy volunteers (six men, median age 24 , range $19-45$ years) served as the control group.

PSYCHOLOGICAL SCORES

Table I shows the psychological scores on the BDI, HAD-A, and HAD-D. On the BDI, a score of $0-10$ is rated as normal, $11-16$ is mild depression, 17-20 is borderline clinical depression, $21-30$ is moderate depression, and greater than 30 is severe depression. With either of the HAD subscales, a score of $0-7$ is considered normal, $8-10$ is mild anxiety or depression, and a score above 10 is definite anxiety or depression, up to a maximum of 21 .

\section{TRANSIT TIMES}

Median (range) WGTT was 42 (10-68) hours in the control group, 14 (6-29) hours in patients with generalised anxiety disorder, 49 (35-71) hours in patients with depression, and 34 (18-66) hours in patients fulfilling DSMIII-R criteria of both anxiety and depression (Fig 1). The WGTT was shorter in patients with anxiety than in patients with depression $(p<0.001)$, and shorter than in controls $(\mathrm{p}<0.001)$. The difference in WGTT between depressed patients and control subjects did not reach statistical significance $(p=0 \cdot 09)$. Table II shows segmental colonic transit times, demonstrating that the faster WGTT in anxiety occurred in all colonic regions.

The OCTT was $75(50-140)$ minutes in the control group, $60(10-70)$ minutes in patients with anxiety, $110(60-180)$ minutes in patients with depression, and 70 (60-90) minutes in patients with both anxiety and depression (Fig 2). In patients with anxiety, OCTT was shorter than in patients with depression $(p<0.01)$, and shorter than in controls $(p<0.05)$. The prolongation of OCTT in depressed patients compared with controls did not reach significance $(\mathrm{p}=0 \cdot 08)$.

In the whole group of psychiatric patients, there was a correlation between WGTT and 


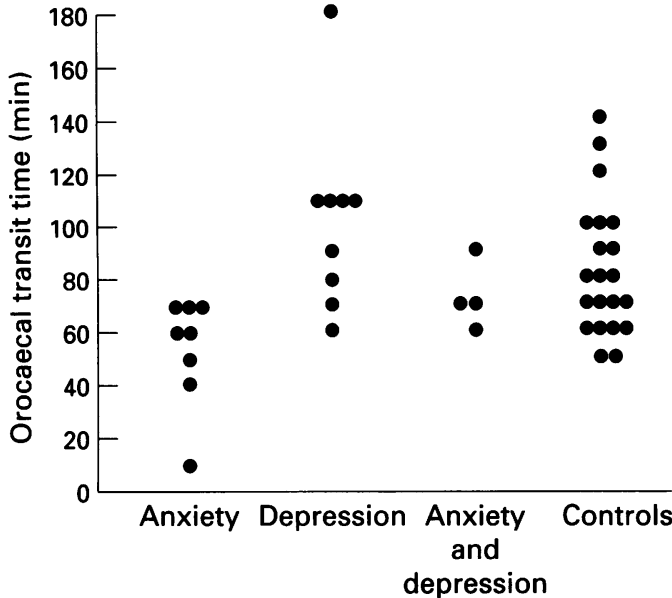

Figure 2: Orocaecal transit times in patients with DSM-III-R criteria of generalised anxiety disorder, or major depression, or both and in controls.

depression scores (Fig 3); WGTT correlated with scores on both the BDI $(r=0.59, \mathrm{p}<0.01)$ and with scores on the HAD-D $(r=0.66$, $\mathrm{p}<0.001)$. There were no significant correlations between OCTT and the psychological scores, although for OCTT and HAD-D, $r$ was $0.44, p=0.06$. In the entire group of 42 patients and controls, OCTT correlated with WGTT $(r=0.47, \mathrm{p}<0.01)$.

\section{BOWEL SYMPTOMS}

In the patients with anxiety, the median number of bowel movements per week was 13 to 16 , and ranged from $5-8$ to $22-26$. In patients with depression the median frequency of defecation per week was lower at 3-4, and ranged from 1 to $17-21 \quad(p<0.05)$. In the control group, the median number of weekly bowel movements was $5-8$, with a range from 2 to 17-21. Using a definition of recurrent abdominal pain and three or more Manning criteria, three of the eight patients with anxiety qualified for a diagnosis of irritable bowel syndrome. Six of the nine patients with depression and three of the four patients with both anxiety and depression qualified for a diagnosis of irritable bowel syndrome. Thus within the entire group of psychiatric patients, 12 of $21(57 \%)$ had irritable bowel syndrome. By contrast, two of the 21 controls $(10 \%)$ fulfilled criteria for diagnosing irritable bowel syndrome $(p<0 \cdot 05)$.

\section{Discussion}

These objective measurements of intestinal transit in patients with affective disorders show that mood disturbances are associated with altered OCTT and WGTT. The WGTT consists predominantly of colonic transit time. Although OCTT comprises gastric emptying as well as small intestinal transit time, small intestinal transit is the same as OCTT when using lactulose alone. ${ }^{19}$ Therefore differences of OCTT in this study are likely to be due to differences in transit through the small intestine.

Patients with anxiety and/or depression often have somatic symptoms including disturbed defecation. Thus constipation is found in almost a third of depressed patients, ${ }^{9}$ but there have been no previous objective studies to support altered intestinal transit in psychiatric patients. Tucker et al, however, did show that personality factors influence stool output in healthy men. ${ }^{20}$ Positive outgoing personality traits were associated with increased stool output. Other studies linking psychological factors and bowel habit have focused on patients presenting with disturbed defecation. There is increased psychiatric disturbance in patients complaining of constipation. ${ }^{4-8}{ }^{21-23}$ However, increased psychopathology is not universally reported in patients attending hospital with constipation, ${ }^{24}$ and in some studies constipated patients with normal transit had increased psychomorbidity, but constipated patients with slow transit did not. ${ }^{2325} \mathrm{~A}$ link between disturbed bowel habit and psychological factors is also strengthened by the increased psychomorbidity seen in patients with irritable bowel syndrome attending hospital. ${ }^{1-3}$

Our study differs from those above because patients with psychiatric illness were studied
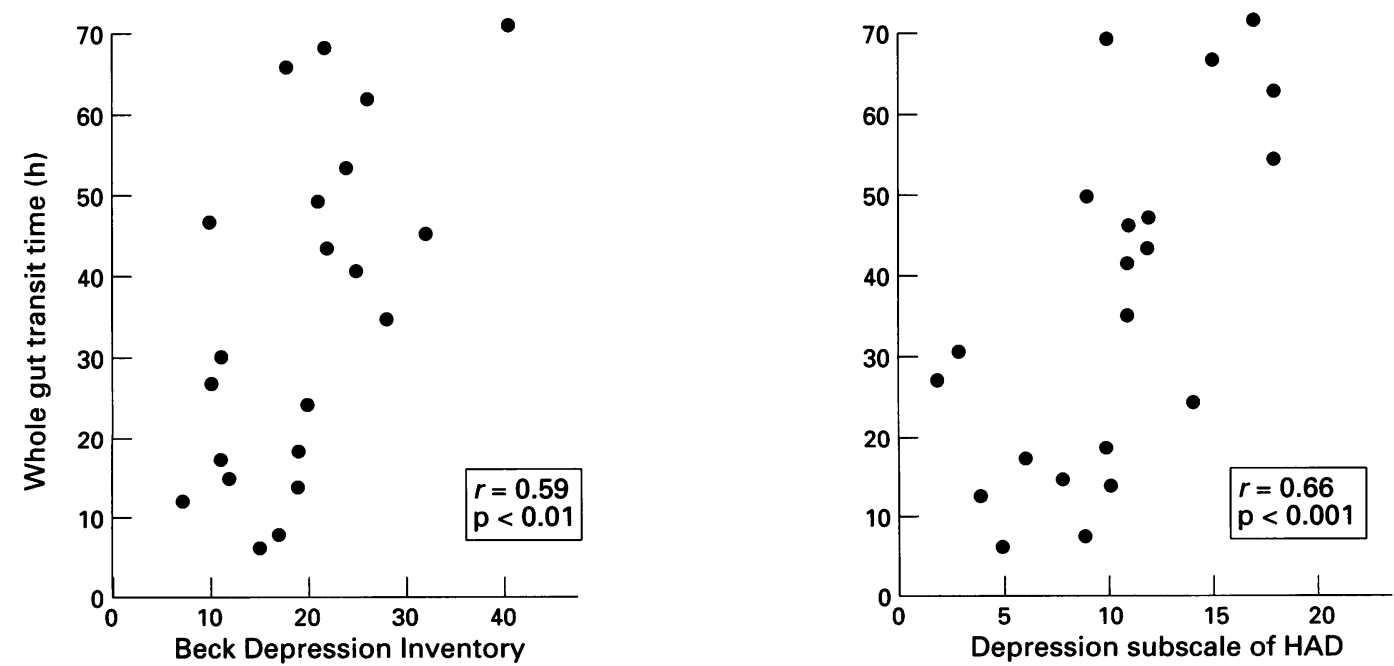

Figure 3: Correlation of whole gut transit times with depression scores (left panel, Beck Depression Inventory score; right panel, depression score of Hospital Anxiety and Depression scale) in patients with generalised anxiety disorder, or major depression, or both. 
rather than patients with bowel symptoms seen by gastroenterologists or surgeons. In the only other study investigating transit in patients with psychiatric disturbance, patients had presented with gastrointestinal symptoms. ${ }^{26}$ Whole gut transit times were shortened in anxiety and prolonged in depression, in keeping with the findings of the current study, but no correlations were found between transit times and psychiatric morbidity scores. By contrast, in our study, patients were all psychiatric outpatients and were not seeing gastroenterologists.

Intestinal transit (both WGTT and OCTT) was faster in anxious patients than in the depressed and control groups. Our finding of shortened OCTT in anxiety is in keeping with the finding that short periods of laboratory induced stress can shorten small intestinal transit in healthy volunteers. ${ }^{27} \mathrm{We}$ also showed that patients with anxiety have accelerated WGTT. This is consistent with the description of some patients with functional bowel symptoms as having 'nervous diarrhoea'. Depression, on the other hand, tended to slow transit, but the prolongation of OCTT and WGTT in depressed patients did not reach significance. A significant difference may have been reached if larger numbers of depressed patients were studied. However, there are practical and ethical difficulties in recruiting psychiatrically ill patients who are not taking any drugs, into a study of this nature. Patients requiring urgent drug treatment or admission to hospital were not eligible. Patients had to be outpatients because relative immobilisation in hospital might slow transit compared with the control group - however, the effects of exercise and immobility on bowel transit are disputed. ${ }^{29-33}$ Although the depressed patients did not have significantly greater transit times, there were significant positive correlations between WGTT and scores on both the BDI and the HAD-D. These correlations provide, for the first time, evidence for an association between severity of depression and colonic inertia. Mechanisms (autonomic neural connections or hormonal) by which mood can alter colonic motor function remain unknown.

Assessment of bowel symptoms was a minor part of this study, yet, interestingly, it showed that the faster intestinal transit of anxious patients was associated with more frequent defecation, whereas the slower transit of the depressed group was associated with less frequent bowel actions. Other studies have shown that frequency of defecation is not correlated with colonic transit time. ${ }^{12}$ 34-36 Symptoms compatible with a diagnosis of irritable bowel syndrome were present in more than half of the psychiatric patients, and were most prevalent in patients with depression. This contrasts with the prevalence of irritable bowel syndrome in the general population of about $20 \%,{ }^{37}{ }^{38}$ but is consistent with studies reporting a prevalence of irritable bowel syndrome in patients with anxiety and depression of about $30-40 \%{ }^{39-41}$

Our findings are consistent with clinical impressions that anxiety is associated with increased bowel frequency, ${ }^{28}$ and depressed patients tend to be constipated. ${ }^{9}$ The transit differences between anxious and depressed patients and the correlation of depression scores with prolonged transit show an effect of mood on bowel motility. Just as acute perturbations of the central nervous system by stress and emotion acutely alter intestinal motility, ${ }^{27}{ }^{42-44}$ so more chronic perturbation of the central nervous system by affective disorder also influences intestinal motor function.

This work was presented to the 1995 autumn meeting of the British Society of Gastroenterology and published in abstract form (Gut 1995; 37 (suppl 2): A47).

1 Creed F, Guthrie E. Psychological factors in the irritable bowel syndrome. Gut 1987; 28: 1307-18.

2 Blanchard EB, Scharff L, Schwarz SP, Suls JM, Barlow DH The role of anxiety and depression in the irritable bowel syndrome. Behav Res Ther 1990; 28: 401-5.

3 Walker EA. Roy-Byrne PP, Katon WJ, Li L, Amos D, Jiranek G. Psychiatric illness and irritable bowel syndrome: a comparison with inflammatory bowel disease. Am $\mathcal{F}$ Psychiatry 1990; 147: 1656-61.

4 Devroede G, Girard G, Bouchoucha M, Roy T, Black R, Camerlain $\mathrm{M}$, et al. Idiopathic constipation by colonic dysfunction. Relationship with personality and anxiety. Dig Dis Sci 1989; 34: 1428-33.

5 Heymen S, Wexner SD, Gulledge AD. MMPI assessment of patients with functional bowel disorders. Dis Colon Rectum 1993; 36: 593-6.

6 Towers AL, Burgio KL, Locher JL, Merkel IS, Safaeian M, Wald A. Constipation in the elderly: influence of dietary, psychological, and physiological factors. $7 \mathrm{Am}$ Geriatr Soc psychological, and

7 Merkel IS, Locher J, Burgio K, Towers A, Wald A. Physiologic and psychologic characteristics of an elderly population with chronic constipation. Am f Gastroenterol 1993; 88: 1854-9.

8 Fisher SE, Breckon K, Andrews HA, Keighley MRB Psychiatric screening for patients with faecal incontinence or chronic constipation referred for surgery. $\mathrm{Br} f \mathrm{Surg}$ 1989; 76: 352-5.

9 Garvey M, Noyes R, Yates W. Frequency of constipation in major depression: relationship to other clinical variables. Psychosomatics 1990; 31: 204-6.

10 American Psychiatric Association. Diagnostic and statistical manual of mental disorders (DSM-III-R). 3rd ed, (revised). manual of mental disorders (DSM-III-R). 3rd ed, (revised). 1987.

11 Gorard DA, Libby GW, Farthing MJG. Influence of antidepressants on whole gut and orocaecal transit times in health and diarrhoea-predominant irritable bowel syndrome. Aliment Pharmacol Ther 1994; 8: 159-66.

12 Metcalf AM, Phillips SF, Zinsmeister AR, MacCarty RL Beart RW, Wolff BG. Simplified assessment of segmental colonic transit. Gastroenterology 1987; 92: 40-7.

13 Spitzer RL, Williams JBW, Gibbon M, First MB. Structured clinical interview for DSM-III-R: non-patient edition (SCID-
$N P$ ). Washington, DC: American Psychiatric Press, 1990 .

14 Beck AT, Ward CH, Mendelson M, Mock J, Erbaugh J. An inventory for measuring depression. Arch Gen Psychiatry $1961 ; 4: 561-71$.

15 Zigmond AS, Snaith RP. The hospital anxiety and depression scale. Acta Psychiatr Scand 1983; 67: 361-70.

16 Talley NJ, Phillips SF, Melton LJ, Mulvihill C, Wiltgen C, Zinsmeister AR. A patient questionnaire to identify bowel disease. Ann Intern Med 1989; 111: 671-4.

17 Talley NJ, Phillips SF, Wiltgen CM, Zinsmeister AR Melton LJ. Assessment of functional gastrointestinal disease: the bowel disease questionnaire. Mayo Clin Proc 1990; 65: 1456-79.

18 Manning AP, Thompson WG, Heaton KW, Morris AF Towards positive diagnosis of the irritable bowel. $B M \mathscr{F}$ 1978; $2: 653-4$.

19 Di Lorenzo C, Dooley CP, Valenzuela JE. Role of fasting gastrointestinal motility in the variability of gastrointestinal transit assessed by hydrogen breath test. Gut 1991; 32: 1127-30.

20 Tucker DM, Sandstead HH, Logan GM, Klevay LM, Mahalko J, Johnson LK, Inman L, Inglett GE. Dietary fibre and personality factors as determinants of stool output. Gastroenterology 1981; 81: 879-83.

21 Preston DM, Pfeffer JM, Lennard-Jones JE. Psychiatric assessment of patients with severe constipation. Gut 1984 25: A582-3.

22 Kamm MA, Hawley PR, Lennard-Jones JE. Outcome of colectomy for severe idiopathic constipation. Gut 1988 29: $969-73$

23 Grotz RL, Pemberton JH, Talley NJ, Rath DM, Zinsmeister AR. Discriminant value of psychological distress, symptom profiles, and segmental colonic dysfunction in outpatients with severe idiopathic constipation. Gut 1994; 35: 798-802. 
24 Read NW, Timms JM. Defecation and the pathophysiology of constipation. Clinics in Gastroenterology 1986; 15: $937-65$.

25 Wald A, Hinds JP, Caruana BJ. Psychological and physiological characteristics of patients with severe constipation. Gastroenterology 1989; 97: 932-7.

26 Chaudhary HR. Study of intestinal transit time in patient with anxiety and depression. F Assoc Physicians India 1989; 37: 156-7.

27 Cann PA, Read NW, Cammack J, Childs H, Holden S, Kashman R, et al. Psychological stress and the passage of a standard meal through the stomach and small intestine in man. Gut 1983; 24: 236-40.

28 Esler MD, Goulston KJ. Levels of anxiety in colonic disorders. N Engl f Med 1973; 288: 16-20.

29 Oettle GJ. Effect of moderate exercise on bowel transit. $G u$ 1991; 32: 941-4.

30 Coenen C, Wegener M, Wedmann B, Schmidt G, Hoffman S. Does physical exercise influence bowel transit in healthy young men? Am 7 Gastroenterol 1992; 87: 292-5.

31 Robertson $G$, Meshkinpour $H$, Vandenberg $K$, James $N$ Cohen A, Wilson A. Effects of exercise on total and segmental colon transit. $₹$ Clin Gastroenterol 1993; 16: segmen.

32 Liu F, Kondo T, Toda Y. Brief physical inactivity prolongs colonic transit time in elderly active men. Int $\mathcal{F}$ Sports Med 1993; 14: 465-7.

33 Sesboue B, Arhan P, Devroede G, Lecointe-Besancon I, Congard P, Bouchoucha M, Fabre J. Colonic transit in soccer players. $\mathcal{F}$ Clin Gastroenterol 1995; 20: 211-4.

34 Krevsky B, Malmud LS, D'Ercole F, Maurer AH, Fisher RS. $1102-12$.
35 Oettle GJ, Heaton KW. Is there a relationship between symptoms of the irritable bowel syndrome and objective measurements of large bowel function? A longitudinal study. Gut 1987; 28: 146-9.

36 O'Donnell LJD, Virjee J, Heaton KW. Detection of pseudodiarrhoea by simple clinical assessment of intestinal transit rate. $B M F$ 1990; 300: 439-40.

37 Talley NJ, Zinsmeister AR, Van Dyke C, Melton LJ. Epidemiology of colonic symptoms and the irritable bowel syndrome. Gastroenterology 1991; 101: 927-34.

38 Jones $R$, Lydeard $S$. Irritable bowel syndrome in the general population. BMF 1992; 304: 87-90.

39 Tollefson GD, Tollefson SL, Pederson M, Luxenberg M, Dunsmore G. Comorbid irritable bowel syndrome in patients with generalised anxiety and major depression. Ann Clin Psychiatry 1991; 3: 215-22.

40 Masand PS, Kaplan DS, Gupta S, Bhandary AN, Nasra GS Kline MD, Margo KL. Major depression and irritable bowel syndrome: is there a relationship? f Clin Psychiatry 1995; 56: 363-7.

41 Dewsnap PA, Gomborone JE, Libby GW, Farthing MJG. The prevalence of symptoms of irritable bowel syndrome among acute psychiatric inpatients with an affective diagnosis. Psychosomatics 1996; 37: 385-9.

42 Almy TP. Experimental studies on the irritable colon. $A m$ f Med 1951; 10: 60-7.

43 Narducci F, Snape WJ, Battle WM, London RL, Cohen S Increased colonic motility during exposure to a stressful situation. Dig Dis Sci 1985; 30: 40-4.

44 Welgan $\mathrm{P}$, Meshkinpour H, Beeler M. Effect of anger on colon motor and electrical activity in irritable bowel syndrome. Gastroenterology 1988; 94: 1150-6. 